$\begin{gathered}\text { EPiC Series in Education Science } \\ \text { Volume 1, 2017, Pages 253-262 }\end{gathered}$
$\begin{gathered}\text { AUBEA 2017: Australasian Universities Build- } \\ \text { ing Education Association Conference 2017 }\end{gathered}$
$\begin{gathered}\text { Education } \\ \text { Science }\end{gathered}$

\title{
Seasonal Usage Pattern of Outdoor Spaces in Educational Precinct
}

\author{
Salman Shooshtarian ${ }^{1^{*}}$, Amrit Sagoo ${ }^{1}$, and Priyadarsini Rajagopalan ${ }^{1}$ \\ ${ }^{1}$ RMIT University, Melbourne, Australia. \\ Salman.shooshtarianermit.edu.au, amrit.sagooermit.edu.au, \\ priyadarsini.rajagopalanermit.edu.au
}

\begin{abstract}
Sustainable open spaces in cities can enhance humans' day to day life. Among the determinants of the quality of outdoor environments, high priority is given to ambient climatic conditions. This research is aimed to explore the usage pattern of outdoor spaces in an educational precinct and discover its linkage to thermal conditions. The target population was the users of the main open spaces of an educational precinct selected as the case study in Melbourne, Australia. The data collection methods included field survey (questionnaire and concurrent measurement) and unobtrusive observation. The data obtained was used to understand the characteristics of usage pattern in the three seasons (spring 2014, summer 2015 and autumn 2015). The results indicated the seasonal usage pattern of the precinct and the significance of function of the place on people's presence outdoors. The research findings are expected to inform guidelines on managing outdoor spaces, particularly within university campuses.

based
\end{abstract}

\section{Introduction}

Sustainable open spaces in cities can enhance humans' day to day life. Among the determinants of the quality of outdoor environments, high priority is given to surrounding microclimatic conditions (Mayer and Höppe, 1987). Microclimate conditions govern the number of attendance and the quality of activities performed in an outdoor space. Due to social, environmental, and financial reasons, the study of usage pattern has become a central agenda in many urban studies and particularly related comfort (Thorsson et al., 2004, Lin et al., 2013). Some studies have found that there is a link between thermal conditions and use of outdoor spaces (Gaitani et al., 2007, Martinelli et al., 2015). For instance, Gaitani et al. (2007) argued that thermal conditions through people's thermal perceptions determine attendance and human activities in outdoor spaces and the level of activities depends on the extent of satisfaction. In contrast, some studies have proved the independence of

* Corresponding author 
usage pattern on thermal conditions (Thorsson et al., 2007, Zeng and Dong, 2015), where the use of certain public places was found to be less correlated to thermal conditions. For instance, Thorsson et al. (2007) found that function of places was the determinant of people's attendance in public spaces of Japan. In this regard, Lin (2009) indicated that “...simple thermal environmental factors or thermal comfort indices cannot fully explain the influence of the thermal environment on the number of people using public spaces and other non-thermal factors ought to be taken into account" (p. 2025). Therefore, this study is aimed to understand the characteristics of usage pattern in open spaces of an educational precinct in Australia, stressing the relationship with seasonal changes.

\section{Methodology}

\subsection{Data collection methods}

The usage pattern in the open spaces of an educational precinct was investigated. Three types of data collection methods were employed: questionnaire survey, unobtrusive observation and concurrent measurements. Field measurements recorded the values of four major microclimatic parameters: air temperature $(\mathrm{Ta})$, wind velocity $(\mathrm{Va})$, relative humidity $(\mathrm{RH})$ and globe temperature (Tg). Furthermore, the local microclimatic conditions were acquired from the Bureau of Meteorology (BOM) local weather station throughout the study period for the study area, Melbourne's CBD. In each season, 15 days were allocated to conduct field surveys and observations: from 9:00 am to 5:00 pm in November 2014 (spring), February 2015 (summer), and May 2015 (autumn). The method used in this study is a standard practice to assess outdoor thermal comfort that has been adopted in previous studies (Spagnolo and de Dear, 2003, Thorsson et al., 2004).

\subsection{Thermal comfort index}

One indicator for assessing the effect of weather conditions in outdoor space is the concept of thermal comfort. Thermal comfort is defined as "...that condition of mind that expresses satisfaction with the thermal environment" (ASHRAE 55, 2010, p. 7). Two models underpin the thermal comfort criteria that dominate comfort research: the steady state heat-balance theory model (Fanger, 1970) and the adaptive models (de Dear et al., 1997). This study drew on the heat-balance theory and assessed the collective effect of four environmental parameters $\left(T_{a}, R H, V_{a}\right.$ and $\left.T_{m r t}\right)$ and two personal factors (level of clothing insulation and activity) on outdoor users. The Physiological Equivalent Temperature (PET) was used as thermal comfort index. PET is built up on the basis of Munich Energy-balance Model for Individuals (MEMI) in 1987 and is technically linked with the Gagge's two-node model parameters (Höppe, 1999). PET values were calculated using Rayman 
Software Package 1.2 that assumes constant values for the level of activity $(80 \mathrm{~W})$ and clothing insulation $(0.55 \mathrm{Clo}$ for spring, $0.41 \mathrm{Clo}$ for summer and 0.81 for autumn). Mean Radiant Temperature (Tmrt) was also calculated to be input into Rayman software using $\mathrm{T}_{\mathrm{a}}, \mathrm{T}_{\mathrm{g}}$ and $\mathrm{V}_{\mathrm{a}}$ (ISO $7730,2006)$.

\subsection{Study sites and target population}

This study was conducted in the context of Melbourne, which has an oceanic temperate climate $(\mathrm{Cfb})$. Melbourne is known for its unpredictable weather conditions where one may experience totally different microclimate conditions from one day to the next (Peel et al., 2007). Three sites, which are the premises of the RMIT University City Campus (RUCC), an educational precinct, were selected as the case study sites (Figure 1). Urban precincts are suggested as appropriate options for the Australian capital cities to develop new smart and sustainable spaces (Yigitcanlar et al., 2008). These three sites are the main open spaces in the study precinct attracting the major users to the university outdoor areas. These sites have different urban features that provide platform for investigation of thermal comfort in various local meteorological conditions. These features are as follows:

Site 1: University Lawn which is used as a recreational space by university students and staff. Due to its compact design, a relatively prevalent form in Melbourne's built up areas. This site contained a number of urban elements including shading devices in a café, timber deck and benches, water features, natural green spaces, and an artificially turfed area which generated varying microclimate conditions.

Site 2: Ellis Court at RUCC was used for different purposes: as the main passage way to other parts of the campus, and a venue for outdoor activities and social events. This site has a $1302 \mathrm{~m} 2$ area and accommodated a range of urban settings, which potentially created an outdoor space with varying local microclimate conditions. Like Site 1, this site had buildings that were heritage listed by the Heritage Council of Victoria. Due to its particular location, this site was largely frequented by students and staff during teaching hours; it is also partly occupied by them in break times.

Site 3: RMIT A'Beckett Urban Square was a $2800 \mathrm{~m} 2$ recreational project, which provided multifunctional courts for outdoor activities, spare modern green spaces, and shading features. This site resembled many commercial outdoor settings in Melbourne's inner city and was designed to serve a wide range of users, mainly university students, staff and other visitors. A few restaurants and cafés were near this site on Stewart Street.

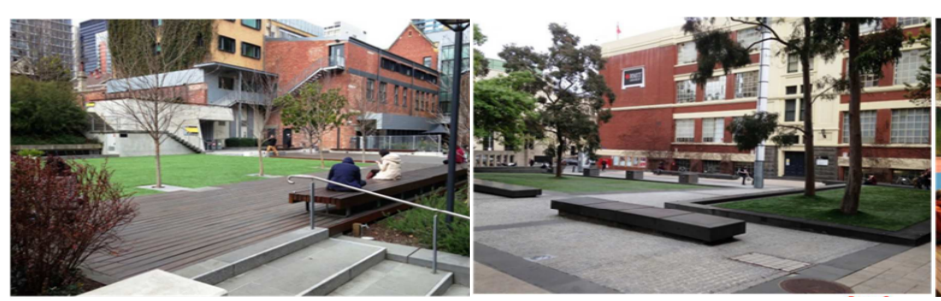

Site 1
Site 2

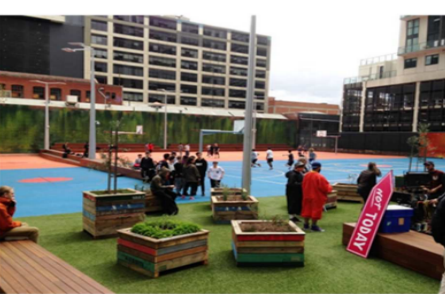

Site 3

Figure 1: View of outdoor usage in the three study sites 
The study population consisted of university students, staff and others using these spaces at the time of surveys. The RMIT University Human Research Ethics Committee approved the administration of the field surveys.

\section{Results \& Discussion}

In total, 1059 questionnaires were collected over the three study seasons: spring (368), summer (413) and autumn (278). Furthermore, during 18 days of unobtrusive observations, 267 sets of data about usage characteristics was gathered in spring (102), summer (90) and autumn (75). The following sections present the results of analysis applied on the data obtained in these field surveys. The results suggest how various seasons may cause changes usage in pattern in outdoor spaces.

\subsection{Weather conditions}

The weather conditions of the study area, Melbourne CBD, in the seven months and within the three seasons, collected from the nearby BOM's weather station are presented in Table 1. The results indicated that Ta in summer was larger compared to that in spring and autumn. The mean maximum $\mathrm{Ta}$ in the last month of summer (February 2015) was greater than that in the last month of spring (November 2014) and autumn (May 2015) by $3.6{ }^{\circ} \mathrm{C}$ and $8.2{ }^{\circ} \mathrm{C}$, respectively. Correspondingly, the highest monthly mean global solar exposure was observed in summer; this was registered as 14.4 M.Jm ${ }^{-2}$, 24.2 M.Jm${ }^{-2}$ and 16.7 M. $\mathrm{Jm}^{-2}$ in September, December and March, respectively. The values of $\mathrm{RH}$ and $\mathrm{V}_{\mathrm{a}}$ were relatively similar over the period as presented in Table 1.

\begin{tabular}{|c|c|c|c|c|c|c|}
\hline & $\begin{array}{c}\mathrm{T}_{\mathrm{a}} \\
\left({ }^{\circ} \mathrm{C}\right)\end{array}$ & $\begin{array}{c}\text { Mean.Ma } \\
\mathrm{x}-\mathrm{T}_{\mathrm{a}} \\
\left({ }^{\circ} \mathrm{C}\right)\end{array}$ & 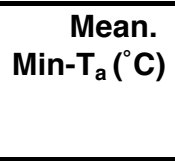 & $\begin{array}{c}\mathbf{R H} \\
(\%)\end{array}$ & $\begin{array}{r}V_{a} \\
\left(m \cdot s^{-1}\right)\end{array}$ & $\begin{array}{c}\text { Monthly } \\
\text { mean global } \\
\text { exposure } \\
\left({\left.\mathrm{M} . \mathrm{Jm}^{-2}\right)}\right.\end{array}$ \\
\hline September & 13.7 & 14.3 & 13.1 & 68.6 & 3 & 14.4 \\
\hline October & 15.7 & 16.3 & 15 & 65.2 & 3 & 18 \\
\hline November & 17.2 & 17.9 & 16.6 & 61.9 & 2.8 & 22.2 \\
\hline December & 18.6 & 19.3 & 18 & 68.2 & 2.8 & 24.2 \\
\hline January & 20.3 & 21 & 19.7 & 64.5 & 3 & 24.6 \\
\hline February & 20.9 & 21.5 & 20.3 & 67.6 & 2.6 & 21.4 \\
\hline March & 17.6 & 18.2 & 17 & 63.3 & 2.5 & 16.7 \\
\hline April & 14.6 & 15.1 & 14.1 & 73.1 & 2.2 & 11.3 \\
\hline May & 13.2 & 13.7 & 12.7 & 71.1 & 3 & 7.6 \\
\hline
\end{tabular}

Table 1: Summary of monthly Melbourne's CBD mean climate conditions. Source: BOM's local weather station

The measurements of two environmental variables $\left(\mathrm{RH}\right.$ and $\mathrm{T}_{\mathrm{a}}$ ) indicated that study sites had similar microclimate conditions throughout the study period with maximum difference of $2.8 \%$ $(\mathrm{RH})$ and $0.9^{\circ} \mathrm{C}\left(\mathrm{T}_{\mathrm{a}}\right)$ in summer. 


\subsection{Frequency and purpose of visit: by season analysis}

To assess the characteristics of usage pattern, the "frequency of use" and "purpose of visit" by participants were elicited in different seasons. Results showed that with change in seasons and drastic decrease in temperature, the number of people who often (daily to several times a week) used the open spaces noticeably reduced (Table 2), from $52.4 \%$ in spring to $37.8 \%$ in autumn. The category of "daily to several times a week" was found to be the main frequency of visits among the study population. The results also suggested that seasonal change was not an important determinant of purpose of visit among the study users. Generally, two categories including "having break, resting, change of environment" $(>30 \%)$ along with "getting fresh air" $(>17 \%)$ were the main purposes of visits during the study seasons.

\begin{tabular}{|c|c|c|c|c|c|c|c|}
\hline & & \multicolumn{2}{|c|}{ Spring } & \multicolumn{2}{|c|}{ Summer } & \multicolumn{2}{|c|}{$\overline{\text { Autumn }}$} \\
\hline & & $\mathbf{N}$ & $\%$ & $\mathbf{N}$ & $\%$ & $\mathbf{N}$ & $\%$ \\
\hline \multirow{4}{*}{ 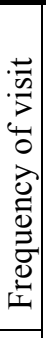 } & Daily to several times a week & 193 & 52.4 & 212 & 51.3 & 91 & $\begin{array}{c}37 . \\
8\end{array}$ \\
\hline & A few times a week & 74 & 20.1 & 97 & 23.5 & 92 & $\begin{array}{c}38 . \\
2\end{array}$ \\
\hline & A few times a month to rarely & 76 & 20.7 & 64 & 15.5 & 45 & $\begin{array}{c}18 . \\
7\end{array}$ \\
\hline & First time & 25 & 6.8 & 40 & 9.7 & 13 & 5.4 \\
\hline \multirow{7}{*}{ 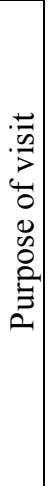 } & $\begin{array}{l}\text { Having break, resting and } \\
\text { change of environment }\end{array}$ & 186 & 37.3 & 191 & 31.4 & 120 & $\begin{array}{c}30 . \\
4\end{array}$ \\
\hline & Getting fresh air & 94 & 18.8 & 105 & 17.2 & 77 & $\begin{array}{c}19 . \\
5\end{array}$ \\
\hline & Playing & 10 & 2.0 & 38 & 6.2 & 26 & 6.6 \\
\hline & Passage to another place & 76 & 15.2 & 98 & 16.1 & 57 & $\begin{array}{c}14 . \\
4\end{array}$ \\
\hline & Having lunch/snack & 78 & 15.6 & 101 & 16.6 & 54 & $\begin{array}{c}13 . \\
7\end{array}$ \\
\hline & Read/write & 17 & 3.4 & 21 & 3.4 & 19 & 4.8 \\
\hline & Meeting/waiting for someone & 38 & 7.6 & 55 & 9.0 & 42 & $\begin{array}{c}10 . \\
6\end{array}$ \\
\hline
\end{tabular}

Table 2: Summary of seasonal statistics of frequency and purpose of visit

\begin{tabular}{|c|c|c|c|c|c|c|c|}
\hline \multirow{7}{*}{ 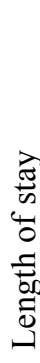 } & \multirow[b]{3}{*}{ Less than 5 minutes } & \multicolumn{2}{|c|}{ Spring } & \multicolumn{2}{|c|}{ Summer } & \multicolumn{2}{|c|}{$\mathrm{mn}^{\text {Autu }}$} \\
\hline & & $\mathbf{N}$ & $\%$ & $\mathbf{N}$ & $\%$ & $\mathbf{N}$ & $\overline{\%}$ \\
\hline & & & & & & & 4 \\
\hline & & 141 & 38.4 & 167 & 40.7 & 131 & 7 \\
\hline & & & & & & & 3 \\
\hline & 5- 10 minutes & & & & & & 2 \\
\hline & & 98 & 26.7 & 130 & 31.7 & 56 & 0 \\
\hline
\end{tabular}




\begin{tabular}{|c|c|c|c|c|c|c|}
\hline & \multicolumn{6}{|l|}{$10-30$ minutes } \\
\hline & More than 30 minutes & 55 & 15 & 42 & 10.2 & 34 \\
\hline \multirow{2}{*}{ 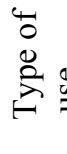 } & Transient & 108 & 20.7 & 225 & 30.4 & 245 \\
\hline & Non-transient & 263 & 79.3 & 739 & 69.6 & 717 \\
\hline
\end{tabular}

Table 3: Summary of statistics of length of stay and type of users

\subsection{Length of stay and type of users}

Length of stay and type of users (transient vs. non-transient) were also assessed using questionnaire survey and unobtrusive observation, respectively. The results indicated that those who stayed outdoor for a few minutes and non-transient were the major users (Table 3). In spring, a larger number of people stayed for longer time $(34.9 \%)$ than those in summer $(27.5 \%)$ and autumn $(22.5 \%)$. The percentage of transient users increased from spring (20.7\%), to summer $(30.4 \%)$ and to autumn $(40 \%)$. These results together proved that seasonal changes and thermal conditions influenced the usage characteristics of outdoor spaces.

\subsection{Thermal adaptive measures and type of activities}

Strategies that participants may take in response to adverse outdoor weather conditions were also investigated using a multiple-choice question in the field surveys. The results indicated that people considered relatively different thermal adaptive measures in various study seasons (Table 4). For instance, moving to shade/sunlight was accounted for $45.2 \%$ of total adaptive measures in summer, $37.1 \%$ in spring and $25.2 \%$ in autumn. Furthermore, given that adding/reducing clothing correspond to $45 \%$ of total votes in autumn $(44.8 \%)$, it can be argued that in outdoor spaces, "move to shade" and "adding to clothing" were the main adaptive strategies adopted in confrontation with adverse weather conditions in hot and cold seasons, respectively. The field observations indicated that in general, resting/talking in two postures (sitting/lying down) accounted for most of the activities in different seasons (Table 4). However, different seasons influenced the frequency distribution of type of activities in the study sites. In summer and spring, around $60 \%$ of people tended to rest and talk 
in sitting and lying positions, whereas in autumn, only $31 \%$ of them preferred these positions and about $27 \%$ took the standing posture in the study open spaces.

\begin{tabular}{|c|c|c|c|c|c|c|c|}
\hline \multirow{7}{*}{ 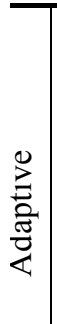 } & & \multicolumn{2}{|c|}{ Spring } & \multicolumn{2}{|c|}{ Summer } & \multicolumn{2}{|c|}{ Autumn } \\
\hline & & $\mathbf{N}$ & $\%$ & $\mathbf{N}$ & $\%$ & $\mathbf{N}$ & $\%$ \\
\hline & Use umbrella/hat & 46 & 10.7 & 44 & 9.2 & 12 & 4.2 \\
\hline & Move to shade /sunlight & 159 & 37.1 & 217 & 45.2 & 72 & 25.2 \\
\hline & Reduce/add clothing & 149 & 34.7 & 100 & 20.8 & 128 & 44.8 \\
\hline & No change & 66 & 15.4 & 115 & 24.0 & 69 & 24.1 \\
\hline & Others (please specify) & 9 & 2.1 & 4 & 0.8 & 5 & 1.7 \\
\hline \multirow{6}{*}{ 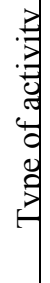 } & Smoking & 4 & 5.3 & 4.5 & 1.4 & 10.5 & 12.0 \\
\hline & Eating/drinking & 14 & 18.4 & 47.5 & 14.7 & 18 & 20.6 \\
\hline & Playing & 1 & 1.3 & 14 & 4.3 & 2.5 & 2.9 \\
\hline & Studying & 4 & 5.3 & 33 & 10.2 & 6 & 6.9 \\
\hline & Standing & 9.5 & 12.5 & 43 & 13.3 & 23.5 & 26.9 \\
\hline & $\begin{array}{l}\text { Resting/talking } \\
\text { down) }\end{array}$ & 43.5 & 57.2 & 182 & 56.2 & 27 & 30.9 \\
\hline
\end{tabular}

Table 4: Summary of seasonal statistics of thermal adaptive measures and type of activity

\subsection{Total number of attendance: by-season and by-site analyses}

The interaction between usage pattern of study sites and thermal conditions during various seasons was investigated using correlation analysis test. This analysis involves an investigation of people's presence outdoors with reference to both individual and collective effect of environmental parameters. Table 5 provides the summary of findings for the correlation test in all seasons.

\begin{tabular}{llllllll}
\hline & & $\mathbf{T}_{\mathbf{g}}$ & $\mathbf{T}_{\mathbf{a}}$ & $\mathbf{R H}$ & $\mathbf{S}_{\mathbf{r}}$ & $\mathbf{V}_{\mathbf{a}}$ & PET \\
\hline Spring & Pearson & $.202^{*}$ & .155 & -.179 & .140 & .008 & .15 \\
$\mathbf{N = 1 0 2})$ & Correlation & & & & & & \\
& Sig. & .042 & .12 & .072 & .162 & .936 & .114 \\
Summer & Pearson & .150 & -.047 & $-.53^{* *}$ & $.308^{* *}$ & -.047 & .031 \\
$\mathbf{( N = 9 0 )}$ & Correlation & & & & & & \\
& Sig. & .159 & .662 & .00 & .007 & .657 & .77 \\
Autumn & Pearson & $.452^{* *}$ & $.638^{* *}$ & -.062 & $.366^{* *}$ & $.234^{*}$ & $0.29^{*}$ \\
$\mathbf{( N = 7 2 )}$ & Correlation & & & & & & \\
& Sig. & .00 & .001 & .607 & .002 & .048 & .011 \\
\hline
\end{tabular}

Table 5: Summary of correlation between physical parameters and number of visitors in various seasons Note: *correlation is significant at the 0.05 level, ${ }^{* *}$ correlation is significant at the 0.01 level, ${ }^{\text {ns }}$ correlation is not signifcant

In spring, it seemed that the number of people attending RUCC open spaces was not statistically associated to PET temperatures $(\mathrm{r}=0.15, \mathrm{P}>0.05)$ and measured environmental parameters, excluding radiant temperature $(\mathrm{r}=0.20, \mathrm{~N}=102, \mathrm{P}<0.05)$. These results, however, did contradict the 
results obtained for summer and autumn. In summer $(\mathrm{N}=92)$, among the monitored parameters, relative humidity $(\mathrm{r}=-0.53)$ and solar radiation intensity $(\mathrm{r}=0.38)$ had the highest correlation with total number of attendance being both significant at the 0.01 level. The results highlighted that among the study seasons, the usage pattern was most influenced by environmental parameters in autumn ( $\mathrm{N}=72)$, as four out of five variables had a significant correlation with the number of visitors. The highest correlation in this season was found for $\mathrm{T}_{\mathrm{a}}(\mathrm{r}=0.63, \mathrm{P}<0.01)$ and $\mathrm{T}_{\mathrm{g}}(\mathrm{r}=0.45$, $\mathrm{P}<0.01)$, followed by $\mathrm{S}_{\mathrm{r}}(\mathrm{r}=0.36, \mathrm{P}<0.01)$ and $\mathrm{V}_{\mathrm{a}}(\mathrm{r}=0.23, \mathrm{P}<0.05)$. Overall, these results showed that people's presence outdoor was significantly influenced by environmental parameters in different seasons. The results of unobtrusive observations at various times of the day, total attendance in particular, were associated with thermal conditions to explore the impact of "time of day" and "microclimate conditions" on spatial visits. Therefore, the number of attendances was plotted against hours and PET values (Figure 2). To quantify the extent of the link between total attendance and these two factors, a polynomial second order regression was applied to the aggregated data. The results suggested that a strong relationship existed between thermal conditions and people's presence in RUCC open spaces. However, there was a disparity regarding the extent of association within the study sites. As juxtaposed in Figure 2, the usage pattern in Site 1 had a roughly similar association with thermal conditions $\left(\mathrm{R}^{2}=0.71, \mathrm{P}<0.01\right)$ as to time of the day $\left(\mathrm{R}^{2}=0.67, \mathrm{P}<0.01\right)$ throughout the study period. In Site 2 , there was an opposite circumstance where the effect of thermal conditions on total attendance was weaker $\left(\mathrm{R}^{2}=0.39, \mathrm{P}<0.05\right)$ than time of the day $\left(\mathrm{R}^{2}=\right.$ $0.68, \mathrm{P}<0.01)$. The former association was also found to be the weakest among the study sites. Similar to Site 2, the number of visitors in Site 3 was more governed by the time of the day $\left(\mathrm{R}^{2}=\right.$ $0.83, \mathrm{P}<0.01)$ than thermal conditions $\left(\mathrm{R}^{2}=0.61, \mathrm{P}<0.01\right)$. The results reflected the role of space function along with thermal conditions in people's usage patterns of outdoor spaces in different seasons.
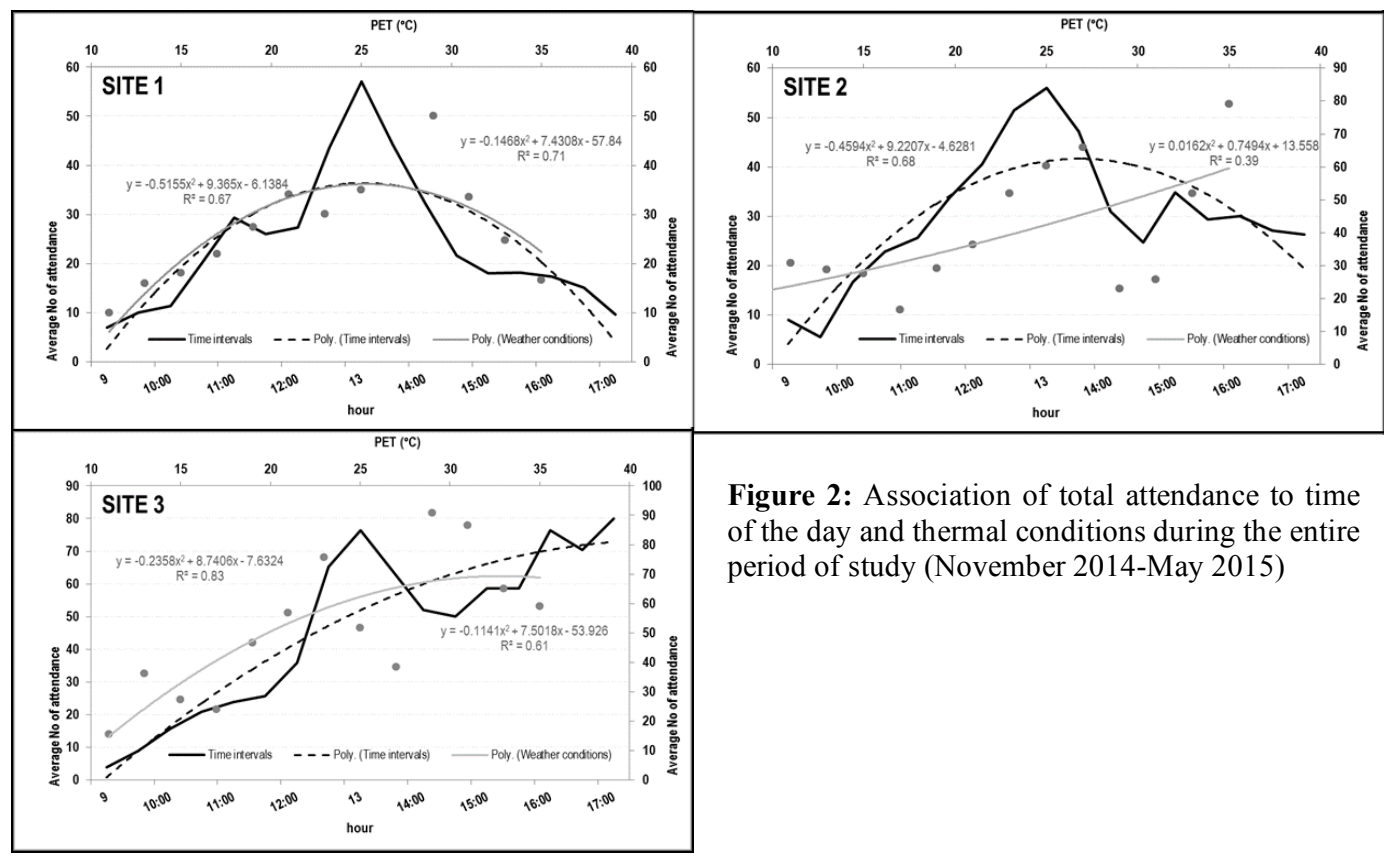

Figure 2: Association of total attendance to time of the day and thermal conditions during the entire period of study (November 2014-May 2015) 


\section{Conclusions}

This study was aimed to investigate a research hypothesis that seasonal changes influence usage patterns of outdoor spaces. Three types of data collection methods (field measurements, questionnaire survey and unobtrusive observation) served to test this hypothesis in an educational precinct. The research findings proved the noticeable impact of three study seasons (spring, summer and autumn) on usage pattern of three open spaces among the university students, staff and other users. The results indicated that seasonal change may influence the frequency of usage, length of stay, type of use, thermal adaptive measures, type of activity and finally number of people's attendance in the outdoor spaces. These results therefore satisfactorily supported the research hypothesis. Further by-site analysis displayed that the function of place along with thermal conditions played a key role in people's attendance outdoors. The research findings are expected to inform guidelines on managing outdoor spaces, particularly within university campuses.

\section{References}

ASHRAE 55 2010. Thermal environmental conditions for human occupancy. Standard 55-2010. Atlanta, USA: American Society of Heating, Refrigerating and Air-conditioning Engineers.

DE DEAR, R., BRAGER, G. \& COOPER, D. 1997. ASHRAE RP-884 Final Report: Developing an Adaptive Model of Thermal Comfort and Preference. Sydney, Australia and Berkely CA, USA: Macquarie Research Limited, Macquaire University and Center for Environmental Design Research, University of California

FANGER, O. P. 1970. Thermal comfort. Analysis and applications in environmental engineering, Danish Technical Press, Copenhagen.

GAITANI, N., MIHALAKAKOU, G. \& SANTAMOURIS, M. 2007. On the use of bioclimatic architecture principles in order to improve thermal comfort conditions in outdoor spaces. Building and Environment, 42, 317-324.

HÖPPE, P. 1999. The physiological equivalent temperature - a universal index for the biometeorological assessment of the thermal environment. International Journal of Biometeorology, 43, 71-75.

ISO 7730 2006. Moderate Thermal Environments- Determination of the PMV and PPD Indices and Specifications of the Conditions for Thermal Comfort.: Geneva: International Organization for Standardization (ISO).

LIN, C.-H., LIN, T.-P. \& HWANG, R.-L. 2013. Thermal Comfort for Urban Parks in Subtropics: Understanding Visitor's Perceptions, Behavior and Attendance. Advances in Meteorology, 2013.

LIN, T.-P. 2009. Thermal perception, adaptation and attendance in a public square in hot and humid regions. Building and Environment, 44, 2017-2026.

MARTINELLI, L., LIN, T.-P. \& MATZARAKIS, A. 2015. Assessment of the influence of daily shadings pattern on human thermal comfort and attendance in Rome during summer period. Building and Environment, 92, 30-38.

MAYER, H. \& HÖPPE, P. 1987. Thermal comfort of man in different urban environments. Theoretical and Applied Climatology, 38, 43-49. 
PEEL, M. C., FINLAYSON, B. L. \& MCMAHON, T. A. 2007. Updated world map of the KöppenGeiger climate classification. Hydrology and Earth System Sciences, 11, 1633-1644.

SPAGNOLO, J. \& DE DEAR, R. 2003. A field study of thermal comfort in outdoor and semioutdoor environments in subtropical Sydney Australia. Building and Environment, 38, 721738.

THORSSON, S., HONJO, T., LINDBERG, F., ELIASSON, I. \& LIM, E.-M. 2007. Thermal Comfort and Outdoor Activity in Japanese Urban Public Places. Environment and Behavior, $39,660-684$.

THORSSON, S., LINDQVIST, M. \& LINDQVIST, S. 2004. Thermal bioclimatic conditions and patterns of behaviour in an urban park in Göteborg, Sweden. International Journal of Biometeorology, 48, 149-156.

YIGITCANLAR, T., CARRILLO, F. J., VELIBEYOGLU, K. \& MARTINEZ-FERNANDEZ, C. 2008. Rising knowledge cities: the role of urban knowledge precincts. Journal of Knowledge Management, 12, 8-20.

ZENG, Y. \& DONG, L. 2015. Thermal human biometeorological conditions and subjective thermal sensation in pedestrian streets in Chengdu, China. International Journal of Biometeorology, $59,99-108$. 